\title{
DESCENTRALIZAÇÃO E DELEGAÇÃO DE AUTORIDADE
}

FRANCISCO GOMES DE MATOS

"Descentralizar pode ser arriscado, mas centralizat é sempre aatastrófica." - HÉLIO BELTRÃo.

A complexidade dos negócios, o avanço da tecnologia moderna, as inovações, a velocidade nas comunicações, a diversificação das linhas de produção e os mercados em transformação e desenvolvimento fazem com que a administração se caraterize como atividade cuja execução demanda, sobretudo, versatilidade. $O$ administrador moderno, porém, não mais se permite concentrar decisões, como fazia o tradicional chefe de emprêsas que se orgulhava de conhecer seu negócio, eis que lhe eram submetidas tôdas as vírgulas das cartas e tôdas as requisições de almoxarifado.

Êsse orgulho fútil, falsamente decantado como "senso de responsabilidade" ou "ônus natural do dirigente", tem sido sintomático da racionalização da insegurança, da desconfiança e da vaidade pessoal de tantos ex-empresários, falidos por não estarem preparados para promover o crescimento da organização.

A emprêsa, como organismo vivo, deve estar apta para a contingência natural e inelutável de crescimento. Não lhe resta outra opção, senão a de expandir para sobreviver.

Francisco Gomes de Matos -- Professor da Faculdade de Administração e Finanças, da Universidade do Estado da Guanabara. 
O crescimento é sinal de vitalidade e garantia de sobrevivência. Portanto, a estrutura empresária deve ser adaptável a novas condições econômicas e humanas; seu planejamento ideal não deve constituir óbice à realidade de seu desenvolvimento. Os desequilíbrios e as disfunções naturais do crescimento, que uma administração com objetivos definidos deve estar apta a corrigir, encontram na dinâmica de pcdêres, acionada pelo exercício regular da delegação de autoridade, a resposta correta para o esfôrço total de expansão.

A descentralização como conseqüência de tesenvolvimento, todavia, não se verifica pela simples multiplicação de estruturas departamentais, pois êsse expediente só lograria manter o processo decisório dentro da mesma perspectiva geral de decisão centralizada. Nem tampouco o fato de haver várias filiais e diretorias em locais distantes significa. a ocorrência de descentralização; normas rígidas, limitałoras da autoridade, pcdem condicionar exageradamente a decisão a um poder central, a "matriz". O que se entendesse, no caso, por descentralização não seria mais do quẹ - espraiar de problemas "trabalhados" por grupos diversos, sob a pressão do aumento do volume de casos, mas sem a necessária autonomia da decisão, único fator capaz de tornar a administração, como um todo, livre para exercer suas funções fundamentais de planejar, organizar, dirigir, motivar e controlar.

É através do racional exercício da delegação de autoridade que se consubstancia, na realidade, a descentralização administrativa. E é pela ausência de um sistema de delegação que muitas emprêsas, ao enfrentarem o problema do crescimento, comprometem sèriamente sua sobrevivência. O fato, entretanto, de a centralização ser, em geral, perigosa concentração de autoridade e responsabilidade, pelos riscos que acarreta de sobrecarga, burccratização, estafa e perda do sentido técnico de administração, não importa em que a descentralização seja, em si mesma, vantajosa. A descentralização não pode ser reduzida a um passe de mágica para atender a um organismo que se de- 
senvolva velozmente, nem a delegação deverá ser exercida pelo romântico reconhecimento de que se deve "valorizar a pessoa humana" conferindo-lhe responsabilidades.

Com efeito, não é possível descentralizar sem delegar autcridade, mas essa delegação há de ser fruto de uma programação que reflita autênticamente a filosofia de administração pela qual a emprêsa é, de acôrdo com sua própria significação etimológica, uma coordenação de esforços para a obtenção de objetivos comuns. Portanto, definida a filosofia da emprêsa através de políticas gerais e específicas, com diretrizes bem delineadas, cargos e funções determinados, pessoal bem selecionado e treinado, e racional sistema de comunicações, torna-se realidade a delegação, condicionada que esta fica a objetivos claramente definidos, à existência de atribuições específicas para cada cargo e a relações de autoridade nitidamente fixadas. A delegação de autoridade repousa, assim, em chefias que conheçam, treinem e motivem suas equipes, estabelecendo objetivos claros, bem como métcdos e procedimentos para alcançá-los eficientemente.

Em suma, descentralizar - e, conseqüentemente, delegar autoridade - é o recurso de que a administração se vale tanto para garantir sua sobrevivência, quanto para poder expandir sua ação, desenvolvendo o pessoal para os compromissos que o crescimento implica.

Várias pesquisas têm demonstrado que o fracasso das organizações se prende, em grande parte, à falta ou à má utilização da delegação de autoridade. A incapacidade para delegar autoridade foi uma das três principais deficiências levantadas por F. J. GANDET ${ }^{t}$ ccmo causas dos insucessos administrativos de duzentas companhias. JoHN

1) Citado por Koontz e O'Donnell em Princípios de Administração, pág. 94 . 
K. Hemphill ${ }^{2}$, da Comissão de Pesquisas de Pessoal da Universidade do Estado de Ohio, analisando 500 grupos de vários níveis profissionais, constatou que a liderança do grupo está ìntimamente ligada à possibilidade do exercício da delegação: a pesquisa pôde caraterizar $73 \%$ dêsses 500 grupos como "bons ou excelentes líderes", enquanto que aquêles que "nunca, raramente ou ocasionalmente delegaram" - ou seja, $27 \%$ - foram classificados como "regulares, fracos ou maus líderes".

Reforçando essas considerações, HÉlio BELTRÃo constatou em estudo realizado em 1961 para reforma administrativa do Govêrno do Estado da Guanabara as conseqüências terríveis de uma estrutura centralizada. O levantamento a que procedeu sôbre o emperramento do processo administrativo demonstra, de maneira impressionante, os trâmites burocráticos a que estava sujeita uma simples requisição para compra de um remédio: 47 pessoas informavam o processo, que subia 8 vêzes ao conhecimento do Sr. Secretário de Saúde, uma vez ao Sr. Governador, outra à Secretaria de Finanças e, não raro mais de uma vez, ao egrégio Tribunal de Contas. Isso representava uma tira de quase 2 metros de comprimento que Hélio Beltrão exibiu durante um seminário de gerentes realizado no Banco do Estado da Guanabara em 1964.

Por seu turno, MURRAY D. BRYCE, renomado economista canadense, contratado por inúmeros governos, como conselheiro, para planejar bancos de desenvolvimento e estudar problemas relativos ao investimento estrangeiro, revela em seu excelente livro Industrial Development as causas do insucesso de vários projetos industriais, tôdas ligadas à administração, que considera a "chave do sucesso". BRYCE aponta as 10 causas principais de fracasso administrativo que freqüentemente fazem malograr os projetos industriais nos paises em desenvolvimento, levando à bancarrota emprêsas novas e antigas:

2) Citado por Donald A. Laird e Eleanor C. Laird em As Técnicas de Delegar, págs. 38,39 e 40. 
$1 .^{\text {a }) ~ i n c o m p r e e n s a ̃ o ~ d a s ~ f u n c ̧ o ̃ e s ~ d a ~ a l t a ~ d i r e c ̧ a ̃ o ; ~}$

2. ${ }^{\text {a }) ~ f a l t a ~ d a ~ a u t o r i d a d e ~ e ~ d a ~ r e s p o n s a b i l i d a d e ~ n e c e s s a ́-~}$ rias à direção;

$3 .^{\text {a }}$ ) insuficiência de pessoal administrativo;

4. ${ }^{2}$ ) falta de administradores experimentados;

$5 .^{a}$ ) falta de liderança;

6. ${ }^{2}$ ) falta de delegação;

7. a) desconhecimento da importância do custo e dos lucros;

$8^{\text {a }}$ ) falta do emprêgo da contabilidade como instrumento de administração;

9. a) falta de inteligente manejo do pessoal;

10. ${ }^{2}$ ) falta de uma atividade consciente (objetividade).

Sua análise pormencrizada sôbre cada fator mostra que, em essência, as causas se prendem a u'a má caraterização da filcsofia empresária no que concerne à estrutura de autoridade. Ccmo se percebe, os fatôres negativos mencionados no decálogo de BRYCE - má fixação de objetivos, comunicações deficientes, contrôles inadequados, falta de treinamento e liderança etc. - são todos conseqüentes de uma administração centralizada, sem delegação de autoridade.

QUANDO SE DEVE CENTRALIZAR

A descentralização não significa a inexistência de um órgão central que defina a filosofia, as políticas e as diretrizes gerais da emprêsa, e que estabeleça o planejamento global e os contrôles necessários para que não haja quebra da unidade orgânica.

Há, até mesmo, situações de emergência em que o poder de decidir precisa ser centralizado para enfrentar riscos 
de abalo à sobrevivência empresária, quando surge a necessidade de mudanças rápidas na política comercial em função de imprevisíveis alterações na conjuntura a que a emprêsa esteja ligada, direta ou indiretamente.

Numa descentralização em processamento as decisões só serão transferidas dos escalões superiores aos inferiores progressivamente, de conformidade com o que tiver sido planejado a longo e a curto prazos. Decisões quanto à segurança econômico-financeira e à expansão da emprêsa como um todo orgânico e indivisível são de competência da administração geral; grandes decisões exigem grandes podêres.

DESCENTRALIZAÇÃO EM FUNÇÃO DA NATUREZA DAS ATIVIDADES

Certas atividades exigem maior grau de descentralização que outras. Ventas, por exemplo, atividade-fim da emprêsa, só se tornam produtivas quando se faculta aos seuś executivos liberdade de ação e decisão, em virtude das caraterísticas extremamente diversificadas do mercado consumidor. A descentralização em vendas é requisito fundamental na luta com a concorrência, na conquista de mercados, na manutenção de padrões de eficiência e liderança. Por outro lado, o modo de agir da clientela exige que o esfôrço de vendas se concentre nas exigências do consumidor. $\hat{E}$ preciso procurar o freguês, convencê-lo, superar suas objeções, enfim, satisfazer suas necessidades. Ora, a centralização em vendas, retardando o processo decisório, significaria perda de mercado e estagnação.

Finanças, no entanto, é atividade geralmente centralizada e com maior índice de concentração de autoridade, inclusive nas emprêsas que adotam diretrizes nitidamente descentralizadoras. Justificam-no a lucrativilade das operações e a estabilidade da emprêsa. Todavia, certos exageros nessa área podem amarrar e burocratizar excessivamente as decisões, com evidentes prejuízos para a dinâmica da emprêsa e para o pleno exercício da delegação nos departamentos. Contrôle orçamentário e verificação da adequa- 
da realização dos planos aprovados não significam despótico sistema destinado a controlar minúcias de gastos e exagerada contabilização de custos.

O que é importante destacar é que a administração deve estar consciente da importância da delegação para a expansão dos negócios. Advertido quanto ao seu significado, o administrador verificará se the convém ou não adotar práticas descentralizadoras e, na hipótese afirmativa, o que deverá fazer para descentralizar os podêres gradativamente. Cuidará para que a delegação se processe sem açodamento, com pessoal qualificado, com eficiência de contrôles etc., e evitará a desagradável contingência de voltar a centralizar como recurso extremo para correção de falhas ocorridas na delegação. A frustração decorrente dêsse retrocesso administrativo causa profundo abalo na estrutura da emprêsa, com repercussões negativas sôbre o moral do grupo, gerando descrenças perigosas à sua própria sobrevivência.

Excecionalmente, todavia, a recentralização se justifica diante de situações problemáticas, como crises econômico-financeiras, que demandem racionalização de custos, reformulações políticas e reorganização administrativa. Nesses casos torna-se imprescindivel um perfeito sistema de comunicações como medida preventiva da queda do moral do grupo. Vencida a fase crítica, deve-se restaurar o sistema de descentralização administrativa em bases racionais, com planejamento e contrôle adequados.

Se é verdade que a sobrevivência da emprêsa, em momentos excecionais, exige recentralização, a expansão, porém, só se verifica autênticamente com estruturas descentralizadas e efetivo exercício da delegação.

\section{ERROS COMUNS NA DESCENTRALIZAÇÃO}

Num programa de descentralização administrativa não se pode ignorar que a emprêsa é um todo organizado para obtenção de certos objetivos comuns a todos os departa. 
mentos. Portanto, o entendimento de certos gerentes de que descentralização significa independência absoluta é não apenas errôneo, como desastroso; seria como admitir, numa inversão de valôres, que uma parte fôsse mais importante que o conjunto empresário. Mesmo assim, assistimos, tôda a hora, a executivos que advogam uma autonomia que significa horror a qualquer ingerência do poder central e rebeldia a todos os contrôles, numa evidente demonstração de que a emprêsa nessas condições não teria sentido nem razão-de-ser. Estão de tal modo obcecađios pelo orgulho profissional que não vêem o óbvio de que devem servir à emprêsa e não se servirem dela; comportam-se como se o sucesso do seu departamento devesse ser conquistado a qualquer preço, até mesmo em prejuízo da sobrevivência do organismo empresário. Admitir o critério da autonomia absoluta seria estabelecer a desintegração do organismo, dando azo ao aparecimento de verdadeiros "donos da área", dêsses que têm a mania de falar "Não admito intervenções em meu setor!". .

\section{DESCENTRALIZAÇÃo COM EFICIÊNCIA}

A General Motors Corporation é a emprêsa unânimemente citada pelos autores de Administração como exemplo de sucesso com estruturas descentralizadas. Ela faz da descentralização o ponto marcante de sua filosofia empresária, o que explica, pelo menos em parte, porque ela continua sendo a maior emprêsa do mundo, a despeito de todos os embates e contratempos que tem enfrentado nos seus mais de trinta anos de intensa concorrência mundial.

Peter DRucker, que promoveu estudo acurado da organização da General Motors e entrevistou executivos da emprêsa, verificou que "95\% de tôdas as decisões que afetavam suas operações estavam compreendidas dentro da área de autoridade do gerente", alinhando como vantagens dai decorrentes as seguintes:

3) Koontz e O'Donnell, op. cit.. 


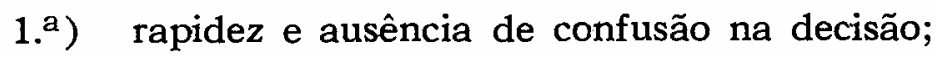

2. ${ }^{a}$ ) ausência de conflito entre a alta administração e as divisões;

3. a) sentimento de eqüidade ao tratar com executivos, confiança em que um trabalho bem feito seria reconhecido e ausência de politicagem na organização;

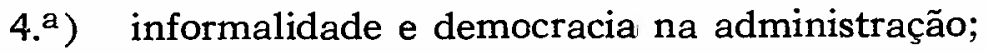

5. a) inexistência de "distância" entre os poucos altos administradores e os muitos administradores subordinados;

6. ${ }^{a}$ disponibilidade de grande reserva de pessoal administrativo com possibilidade de promoção;

7. ${ }^{a}$ ) rápida visão de falhas administrativas através dcs resultados de divisões competidoras semi-independentes;

8. a) ausência de "administração por editais" e presença de informações e considerações completas em relação às decisões da administração central.

Os itens supracitados expressam, em síntese, o vigor de uma administração com objetivos bem definidos e relações harmoniosas, destacando-se como resultados positivos e garantidores de uma vitoriosa política de expansão os itens 6 (reserva de pessoal promovivel) e 7 (contrôle espontâneo e automático de resultados, mediante sadia competição interdepartamental ).

\section{O CONTRÔLE NA DESCENTRALIZAÇÃo}

O êxito de uma administração descentralizada está estreitamente ligado a um racional sistema de contrôle. $O$ chefe não pode "abrir mão", incondicionalmente, das funções de planejar e controlar, pois se a primeira é preparatória de decisões acertalas, a outra é garantidora do acêrto dessas decisões. Através do contrôle evita-se o risco da desinte- 
gração das diretrizes gerais; mantém-se unificada a ação total da emprêsa.

Descentralizar não é, como muitos pensam, "passar a bola adiante", com as nefastas consequiencias que os desencontros de ordens, a diversificação de atitudes e as decisões contraditórias determinam. Diz-se, quando isso ocorre, que falhou a descentralização, relega-se à descrença a delegação, racionalizam-se as atitudes autocráticas e centralizadoras, emperra-se o sistema empresário, freia-se o progresso, preparam-se as decisões à base de quilos de papel e quilométricos processos, adotando-se como cota-praxe a proposição "sobe à consideração da autoridade superior", num sistema suicida de concentração de podêres e fuga de responsabilidades. Os custos aumentam, diminui a produtividade individual, perde-se a consciência grupal. Ocorrem, então, falta de entusiasmo, desinterêsse, ausência de iniciativas, desestímulo à criatividałe e as conseqüências naturais: "fazer serão", "horas extras de traba1ho". . . e muita pressão do alto para que o "serviço saia". Mas, "não se corre o risco". . . Como se o maior risco não fôsse o de centralizar.

Ao delegar, o chefe assume o risco natural dos erros que vierem a ser cometidos. Quando o chefe exerce contrôle rígido sôbre o delegado, inibe-o; quando o censura impiedosamente pelos erros, intimida-o, induzindo-o ao "mêto pela responsabilidade"; a combatividade do subordinado irá diminuindo à medida que seus erros forem negativamente reforçados pela chefia.

Só o chefe tem condições para avaliar sua equipe e dizẹ o nível de delegação de cada subordinado. E é através do exercício da delegação que o chefe irá verificar a capacidade dos seus funcionários para receber encargos. Quando os erros se repetem apesar das instruções dadas, do acompanhamento e do contrôle iniciais; quando o funcionário sobrecarrega a chefia com consultas constantes; quando "amarra" os problemas para resolvê-los "com o tempo" ou simplesmente não resolvê-los, relegando-os ao 
esquecimento, então a chefia verifica a que atribuir essa situação: se à indisciplina, à falta de interêsse ou à incapacidade do funcionário. $\mathrm{E}$ tomará as providências cabíveis a cada caso.

\section{CONTRÔLES DEFICIENTES E INEFICIENCIA}

Se não houver um sistema racional de contrôle, o administrador não terá condições para analisar o risco da autori= dade delegada. Com isso não poderá exercer sua função supervisora, corrigindo erros e gratificando acertos. $O$ risco que o administrador deve correr ao delegar será, tanto quanto possivel, um "risco calculado". Sem contrôle o administrador não terá meios para exercer ação preventiva, expondo-se a constatar tardiamente fracassos irrecuperáveis que lhe reforçarão negativamente a descrença na delegação. A falta de contrôle ou a existência de contrôles deficientes acarretam insegurança à chefia que, ao invés de aparelhar-se adequadamente, passa a usar de subterfúgios e racionalizações para concentrar cada vez maior poder de decisão. Como consequiência, seus subalternos deixam de errar por não terem oportunidade de fazê-lo, mas, em contrapartida, os erros da chefia se acumulam em progressão geométrica, pondo em risco a própria segurança dos negócios. O chefe se acostuma à idéia de que é impossível delegar, e não delega, até que um dia verifica não mais poder suportar o pêso das responsabilidades. Essa verificação corresponde, quase sempre, à falência, à venda do negócio ou à moderna saída pelo enfarte. Mas pode também corresponder à contratação de técnicos de administração que lhe dêem a estrutura necessária para que o processo decisório se torne dinâmico, seguro e eficiente, com maior delegação de autoridade. $\mathrm{E}$, então, nem tưdo estará perdido.

\section{ATITUDES ERRÔNEAS DO ADMINISTRADOR}

Por tradição, alguns administradores conservam hábitos e atitudes administrativos incompatíveis com o crescimento da organização. Às sérias responsabilidades que a expan- 
são lhes conferiu somam o conjunto de tarefas rotineiras e de significação subalterna que continuam a executar por inércia ou inadvertência. Não percebem que o progresso em chefia é qualitativo e rão quantitativo. Porque quanto maiores forem as responsabilidades, tanto maior o rigor seletivo quanto ao nível e à natureza das decisões.

A dinâmica de uma emprêsa não é rigorosamente retratada por organogramas bem traçados, nem tampouco por teóricas relações de linha, em diagramas ou fluxogramas que não correspondem a uma "realidade vivida", onde os níveis de decisões se hierarquizam por sistemas racionais de administração.

Para que o chefe possa - em qualquer nível, mas especialmente nos escalões superiores - exercer as funções que lhe são típicas (planejar, organizar, motivar e controlar) é mister que selecione seus encargos, distribuindo ser: tempo em graus de importância. Quando o chefe se ocupa com minúcias delegáveis a funcionários de menor categoria está sendo anti-econômico, está onerando os recursos da emprêsa, quase sempre inconscientemente. Nisso reside, muitas vêzes, o trágico da questão: êle pensa que se está "matando" pela emprêsa e, na verdade, êle a sacrifica, acumulando quefazeres e, conseqüentemente, emperrando o processo decisório. Daí decorrem a falta de oportunidade para que os subordinados se desenvolvam e suas resultantes inexoráveis: desestímulo, falta de iniciativa e criatividade, oposição, ciúmes e absentismo.

\section{PROMOÇÃO MAL ORIENTADA}

É mais corrente do que se pensa o chefe, ao ser promovido, tratar o substituto em seu cargo anterior como eterno aprendiz. Não larga os encargos antigos: limita-se a torná-lo seu "atendente" a quem dá ordens para fazer. "Éle não está preparado para a delegação" - dizem alguns dos que agem dessa forma; outros nem corisideram o problema, julgando natural terem de preocupar-se em dôbro. É que o chefe está convencido ou de que só êle é capaz 
de realizar, ou de que só êle deve realizar. No primeiro caso falta-lhe confiança no funcionário, que passa a sentir-se frustrado, inseguro e inibido a qualquer esfôrço irovador ou cooperação extraordinária. No segundo caso. quase sempre, é o chefe que está inseguro, por receio de ver-se superado.

O chefe não delega, também, por não ter seu trabalho planejado, não dispondo, portanto, nem de tempo nem de material (normas de serviço etc.) para instruir e controlar.

Falta de delegação é conseqüência, ainda, das deficiências de comunicação do chefe. Não sabe dizer, só sabe fazer, o que sempre fêz foi fazer, então continua fazendo, independentemente das promoções que venha conquistando. Quanto mais sobe na escala hierárquica, tanto mais desconfia dos outros; quanto mais enfeixa responsabilidades, tanto mais representa para a emprêsa perda de produtividade. Repete-se o velho e sempre atual refrão: "perde-se um bom funcionário e ganha-se um mau chefe".

Para eliminar a tendência dos chefes em se julgarem insubstituiveis - e, com isso, não delegar, nem treinar o seu pessoal - deve-se condicionar sua promoção à formação de substitutos, tornando essa prática uma diretriz pùblicamente reconhecida na emprêsa.

\section{CONDIÇÕES BÁSICAS PARA DELEGAR}

Há duas condições imprescindíveis ao exercício adequado da delegação:

- estrutura orgânica bem definida, com um esquema de autoridade onde as relações estejam claramente estabelecidas, de modo que cada um saiba qual é sua posição na emprêsa;

- descrição, por escrito, de cada cargo, com suas atribuições, responsabilidades e limites de autoridade (competência). 
Deve-se dar ampla divulgação a êsse documento entre o pessoal da emprêsa; só assim será possível garantir condições funcionais básicas para um programa entre as chefias, de estímulo à delegação. Com base nesses elementos será possível desenvolver programas de treinamento intensivo sôbre a delegação e o processo decisório.

A prática da delegação, tcdavia, como, a rigor, de tôdas as técnicas administrativas, só se tornará rsalidade pelo exemplo da cúpula. Se os altos administradores são centralizadores, como esperar que as chefias médias aceitem as recomendações de que deleguem? Com a concentração da autoridade os administradores tornam-se irritadiços, rígidos, extremamente exigentes: exercem contrôle permanente sôbre seus subalternos, cobrando-lhes, a todo momento, providências e encargos. Nesse clima de designações constantes e constante contrôle, como pretender estimular a delegação?

\section{CONCLUSÕES}

Quem defende a democracia como regime político e a livre-iniciativa como sua expressão vitalizadora nos negócios não tem como deixar de reconhecer a delegação de autoridade como instrumento de humanização e democratização da emprêsa, que estimula o pessoal à livre expressão, à iniciativa e à efetiva participação nas decisões.

Pela descentralização abre-se campo às inovações, estimulam-se a busca de soluções novas, a aplicação de linhas de atuação, a conquista de mercados, as modificações tecnológicas e o desenvolvimento do pessoal.

O que caracteriza a descentralização é a progressiva autoridade para que os problemas sejam decididos na própria área de realização do trabalho, "em cima do fato", na linha executiva, e não por "órgãos centrais", distantes da realidade.

Portanto, ao falar em descentralização administrativa e em delegação de autoridade, é mister não descurar das 
funções fundamentais da administração. Consoante o clássico esquema de FAYOL, o administrador pode delegar previsão, orǵanização, coordenação e até contrôle, mas o comando é indelegável. Através da autoridade êle exercita sua função essencial: decidir. Previsão e organização preparam essa decisão, assim como a coordenação e o contrôle põem à prova a sua eficiência para novas decisões e planejamentos.

A descentralização não pode representar quebra na unidade doutrinária e dinâmica da emprêsa, nem na integração do pessoal, com grande diversificação na estrutura da autoridade. Não se quer substituir um regime de centralização do poder - com a rigidez emperradora de execuções rotineiras, excessivas responsabilidades, barreira ao desenvolvimento pessoal, engarrafamento e deturpação das comunicações - pelo caos em que todos mandam a seu modo, com tremendo desgaste em choques de prestígio, dualidade de decisões e conflitos de competência por falta de unidade de comando e de continuidade administrativa.

Para que haja descentralização eficiente e efetivo sistema de delegação de podêres são precisos perfeita infra-estrutura administrativa, objetivos, políticas, autoridade e responsabilidades definidos e, finalmente, coordenação e contrôles que garantam a qualidade e a firmeza de um eficiente comando. 